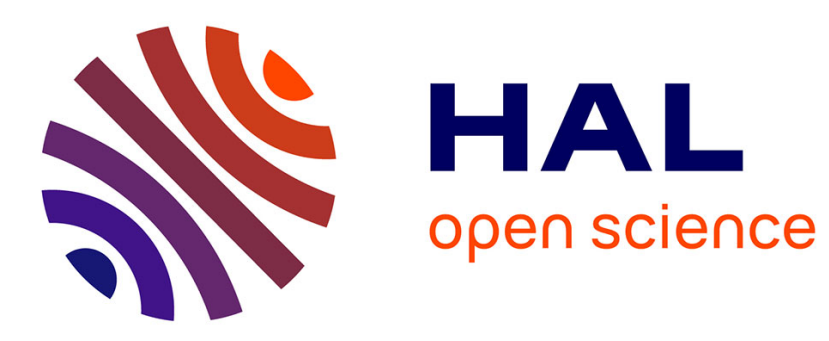

\title{
Analytical and experimental study of feed rate in high-speed milling
}

\author{
Bassem Gassara, Gilles Dessein, Maher Baili, Moncef Hbaieb, Wassila Bouzid
}

Saï

\section{- To cite this version:}

Bassem Gassara, Gilles Dessein, Maher Baili, Moncef Hbaieb, Wassila Bouzid Saï. Analytical and experimental study of feed rate in high-speed milling. Machining Science and Technology, 2013, vol. 17, pp. 181-208. 10.1080/10910344.2013.780537 . hal-00840580

\section{HAL Id: hal-00840580 \\ https://hal.science/hal-00840580}

Submitted on 2 Jul 2013

HAL is a multi-disciplinary open access archive for the deposit and dissemination of scientific research documents, whether they are published or not. The documents may come from teaching and research institutions in France or abroad, or from public or private research centers.
L'archive ouverte pluridisciplinaire HAL, est destinée au dépôt et à la diffusion de documents scientifiques de niveau recherche, publiés ou non, émanant des établissements d'enseignement et de recherche français ou étrangers, des laboratoires publics ou privés. 


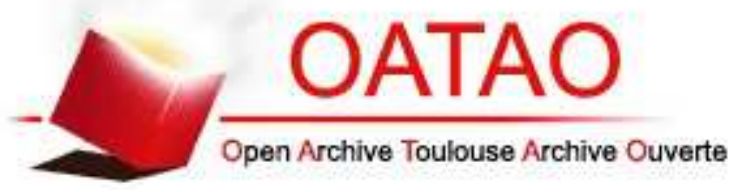

\section{Open Archive Toulouse Archive Ouverte (OATAO)}

OATAO is an open access repository that collects the work of Toulouse researchers and makes it freely available over the web where possible.

This is an author-deposited version published in: http://oatao.univ-toulouse.fr/ Eprints ID: 9037

To link to this article: DOI:10.1080/10910344.2013.780537

http://dx.doi.org/10.1080/10910344.2013.780537

\section{To cite this version:}

Gassara, Bassem and Dessein, Gilles and Baili, Maher and Hbaieb, Moncef and Saï, Wassila Bouzid Analytical and experimental study of feed rate in high-speed milling. (2013) Machining Science and Technology, vol. 17 ( $\left.\mathrm{n}^{\circ} 2\right)$. pp. 181-208. ISSN 1091-0344 


\title{
ANALYTICAL AND EXPERIMENTAL STUDY OF FEED RATE IN HIGH-SPEED MILLING
}

\author{
Bassem Gassara ${ }^{1,2}$, Gilles Dessein ${ }^{2}$, Maher Baili ${ }^{2}$, Moncef Hbaieb ${ }^{1}$, and \\ Wassila Bouzid Saï \\ ${ }^{1}$ Unité de Génie de Production Mécanique et Matériaux, ENIS, Sfax-Tunisie, Tunisia \\ ${ }^{2}$ Université de Toulouse, INP/ENIT, LGP, Tarbes Cedex, France
}

In the context of high-speed milling (HSM), during the machining process dynamic machine response has to be identified. To achieve this, we have to calculate the feed rate evolution in linear and circular interpolation according to dynamic performance of machine. In addition to that, actual trajectory for transition passages between two interpolations must be estimated with take into account of specific machining tolerances. This article proposes a model of machine tool behavior for a tool path with linear and circular interpolations and machining cycle time prediction. The method involves subdividing the trajectories into elementary geometries according to the type of interpolation (circular or linear). At points where different trajectories meet, there is often a discontinuity in curvature or in tangency, which decreases the feed rate. At the points of discontinuity in tangency, a fillet radius is inserted. In this article, the influence of the geometry for elementary trajectories was determined. Then, the value of the fillet radius between linear and circular contours in different combinations was modeled. An industrial application was carried out in order to validate models and to determine the influence of feed rate evolution on the machining cycle time.

Keywords feed rate, fillet radius, high-speed milling, tangency and curvature discontinuity

\section{INTRODUCTION}

In high-speed milling (HSM), the important feed rates and accelerations of the axes solicit the structure of the machine and its numerical control (Bearee et al., 2004; Erkorkmaz and Altintas, 2001). So, it is difficult to control the machine response. For example, the actual machining time is often very high compared with the time estimated by the CAM software (Moneral and Rodriguez, 2003; Siller et al., 2006). Indeed, during the machining process, the feed rate does not always reach the programmed

Address correspondence to Bassem Gassara, Unité de Génie de Production Mécanique et Matériaux, ENIS, route Soukra Km 3.5-B.P. 1173-3038 Sfax-Tunisie, Tunisia. E-mail: bassem.gassara@enit.fr 
value (Albert et al., 2007; Dugas et al., 2002; Pateloup, 2005; Tapie et al., 2007). Erkorkmaz and Altintas (2001) and Pessoles et al. (2010) have presented a review of the analytical methods for calculating the feed rate according to the kinematical parameters of the machine.

For the machining of complex workpieces, the tool path generated by the CAM software can be composed of many elementary interpolations shared in linear (G1) and circular (G02 and G03) interpolations. The large number of these elementary interpolations generates different discontinuities in the path. So, a significant instability of the real feed rate will be observed. As a result, the machine slow downs at each transition of interpolations and actual feed rate is much lower than the programmed one.

In the context of HSM, primarily, it is necessary to adapt the tool path to rapid piloting of the machine and to respect the maximum consumed power. To make the trajectories continuous, two methods are possible (Held and Spielberger, 2009; Pateloup et al., 2010; Rauch et al., 2009; Tang, 2006). The first involves adding a circle arc in the crossing of discontinuity in tangency (Dugas et al., 2002; Pateloup et al., 2004). The second is to estimate the trajectory with polynomial function (Heng and Erkorkmaz, 2010; Pessoles et al., 2012). Then, the machine must have a rigid structure adapted to these conditions. Moreover, the performances of the numerical control unit (interpolation cycle time, look ahead, etc.) and the kinematical characteristics of the machine have an influence on the feed rate variation (Lavernhe, 2008; Wang and Cao, 2012; Yong and Narayanaswami, 2003). Indeed, the machine, which has a high Jerk, permits reduction of the acceleration and deceleration effects which reduces the impact of a discontinuity on the feed rate evolution (Pateloup et al., 2004).

Tool paths can be expressed using straight lines, circle arcs and polynomial interpolation, as described in (Helleno and Schützer, 2006; Sinumerik, 2006). For these authors, the three various types are related to the control unit. For machining operations, there was a discontinuity in curvature or in tangency when changing direction. This generates slower movement. Therefore, the machining cycle time increases.

The discontinuity in tangency has a great impact on the feed rate evolution. To remedy this problem, one of the solutions used is to replace the discontinuity in tangency by the discontinuity in curvature (continuity in tangency). In the literature, several works have been interested in modeling of the fillet radius at the point of discontinuities in tangency which was in relation with the surface tolerance $\varepsilon$. This modeling was applied to a path on linear-linear contour (Dugas et al., 2002; Pateloup et al., 2004; Pessoles et al., 2012). In this article, an advanced modeling method of the fillet radius is presented. We applied this method on tool paths with linear and circular interpolations (as shown in Figure 1). For the modeling, the tool path is discretized into several blocks with discontinuity in tangency 


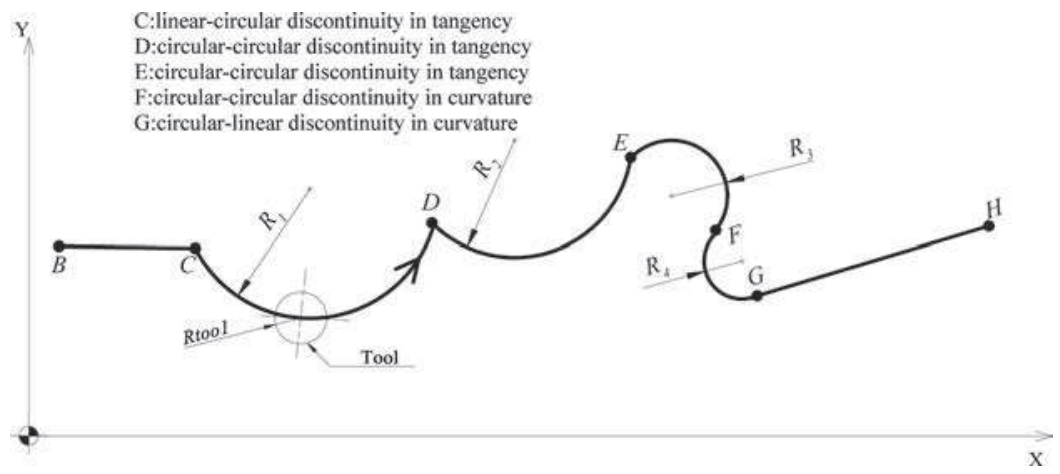

FIGURE 1 Discontinuity in tangency and in curvature.

and curvature. The discontinuity in tangency between two interpolations (at point B) was replaced by a curvature discontinuity by adding circle arc, which is a function of the tolerance $\varepsilon$ (as shown in Figure 2). The establishment of this model allows us to calculate the feed rate. Finally, an experimental study was carried out on a HSM machine in order to verify the developed models.

\section{TOOL PATH MODELING}

In this part, a geometrical model of tool path is presented. For the modeling, the tool path must be discretized into several blocks which have a discontinuity in tangency between them.

In this work, the considered trajectory of tool center is generated by CAM software.

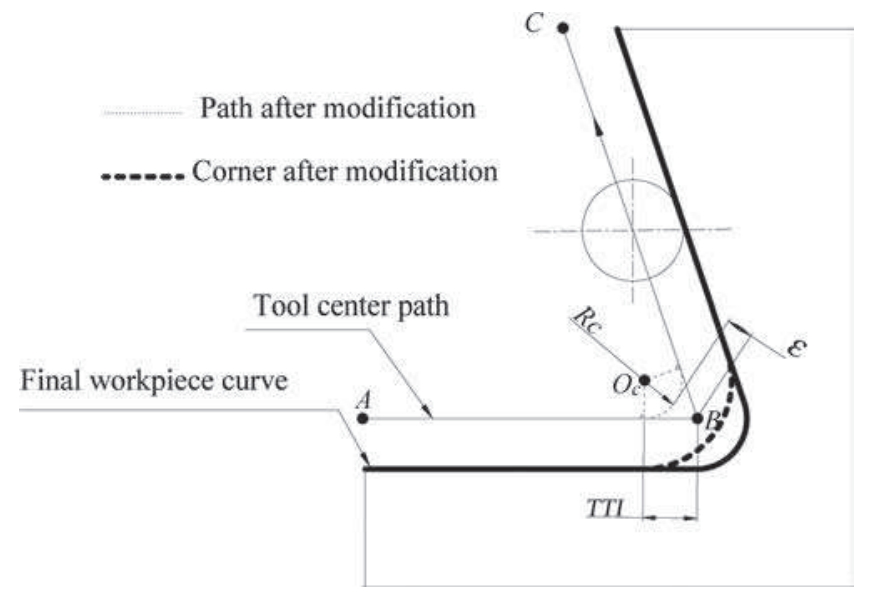

FIGURE 2 Modification of the corner geometry. 


\section{Influence of Tool Path Geometry on the Type of Discontinuity}

For machining operations, the tool path can contain a discontinuity in curvature or in tangency at the point of a direction change. This slows down the machine. The type of this discontinuity depends on orientation angle $\gamma$ representing in Figure 3(a) for the linear-linear contour.

The equation of the orientation angle $\gamma$ for the linear-circular contour (Figure 3(b)) has the following form:

$$
\gamma=90+\frac{\theta}{2}-\kappa+\alpha
$$

The equation of the orientation angle $\gamma$ for the circular-circular contour (Figure 3(c)) has the following form:

$$
\gamma=\frac{\theta_{1}}{2}+\frac{\theta_{2}}{2}+\kappa_{1}-\kappa_{2}
$$

From Equations (1) and (2), two cases of the discontinuity are distinguished:

- Discontinuity in curvature (D.c.) : $\gamma=90^{\circ}$ for the linear-circular contour and $\gamma=0^{\circ}$ for the circular-circular contour.

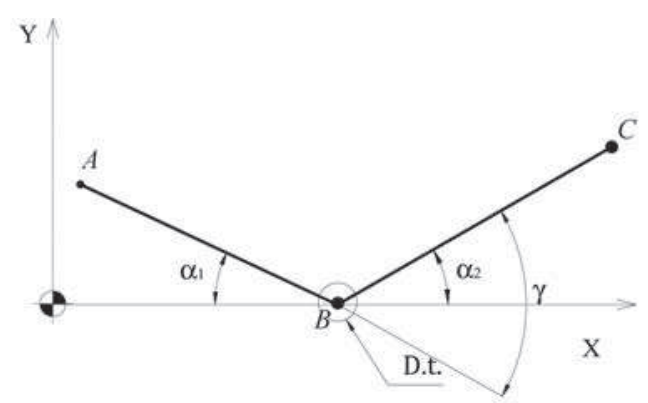

a. Linear-linear contour.

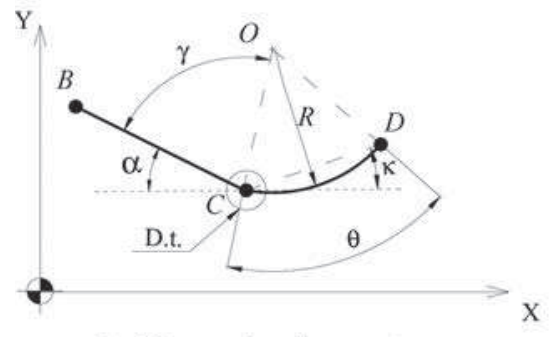

b. Linear-circular contour.

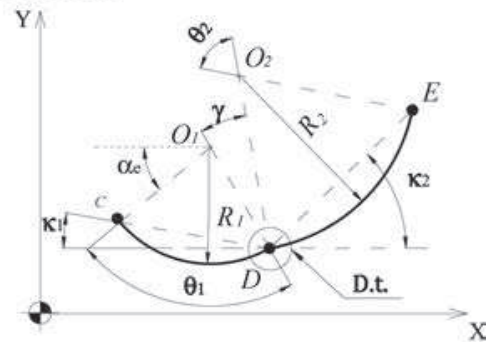

c. Circular-circular contour.

FIGURE 3 Elementary tool path. 


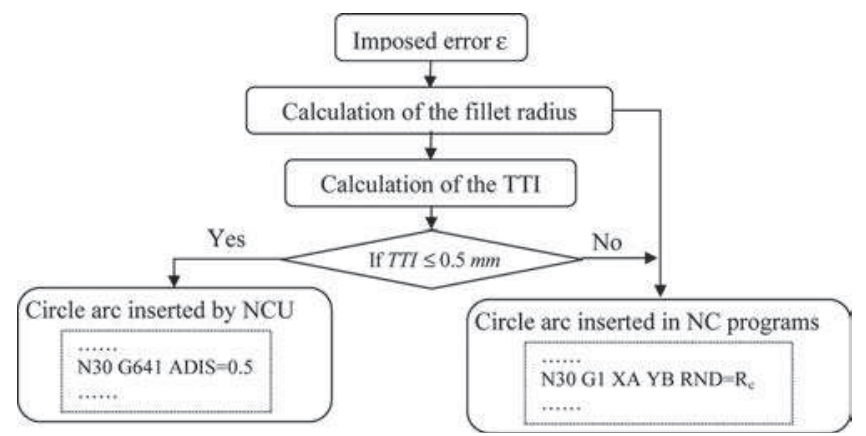

FIGURE 4 Recursive algorithm for fillet radius modeling.

- Discontinuity in tangency (D.t.): $0^{\circ}<\gamma<180^{\circ}$ for the linear-circular contour and for the circular-circular contour.

The orientation angle $\gamma$ has a great influence on the type of discontinuity and the feed rate evolution. It is determined from the points coordinates using a geometry equation. In the following part, a fillet radius modeling was developed in two steps. The first step permits to calculate the angle $\gamma$ basing on the points coordinates. The second step consists of modeling the fillet radius value between circular-circular interpolations in relation to the tolerance $(\varepsilon)$ imposed in the piece design.

\section{Fillet Radius Modeling}

For adapting the tool path to rapid piloting of the machine and in order to reduce the machining cycle time, the discontinuity in tangency has been replaced by discontinuity in curvature. This can be possible by adding an arc of circle which depends on imposed error $(\varepsilon)$.

The modeling of the fillet radius can be presented by two methods. In the first, the fillet radius between the blocks is defined with numerical control (NC) function of the tangential displacement mode (G641) of Sinumerik language (Sinumerik, 2006). In this case the value of the fillet radius depends on the distance tolerance of trajectory interpolation (TTI) (as shown in Figure 2) which is the tolerance of interpolation of the trajectory. The distance must be specified with $\mathrm{ADIS}^{1}$, the circle arc is inserted by numerical control unit (NCU). In the second method, the fillet radius between the blocks can be defined with a modal instruction $(\mathrm{RNDM})$ or a not modal instruction (RND), the circle arc is inserted in NC programs (Figure 4).

${ }^{1}$ Programmable smoothing characteristics (This function permits to specify the value of the TTI). 
As said before, the machine slows down on the level of discontinuities in tangency. So, the control unit allows a non-null feed rate if it has an error. This creates an arc of a circle that depends on imposed error $\varepsilon$ on orientation.

According to Dugas (2002), the fillet radius on the level of discontinuities in tangency is in relation with the error tolerance $\varepsilon$ and the orientation angle $\gamma$ (as shown in Figure 5). This modeling was applied to a path on linear-linear contour.

The fillet radius is given by in Equation (3).

$$
R_{c}=\varepsilon \frac{\cos \left(\frac{\gamma}{2}\right)}{1-\cos \left(\frac{\gamma}{2}\right)}
$$

However, all the controllers never use this definition. They use the TTI instead of tolerance $(\varepsilon)$ (Dugas, 2002) (Figure 5).

The TTI is given by:

$$
T T I=\varepsilon \frac{\sin \left(\frac{\gamma}{2}\right)}{1-\cos \left(\frac{\gamma}{2}\right)}
$$

In this article, the fillet radius $R_{c}$ is calculated for various combinations of path (linear-circular and circular-circular).

The step of modeling as follows:

- Generation of the numerical control intermediate (NCI) files (points coordinates),

- Calculation of the angle $\gamma$ from the points coordinates between two interpolations,

- Calculation the fillet radius adding at the discontinuity in tangency in relation to the imposed tolerance $\varepsilon$.

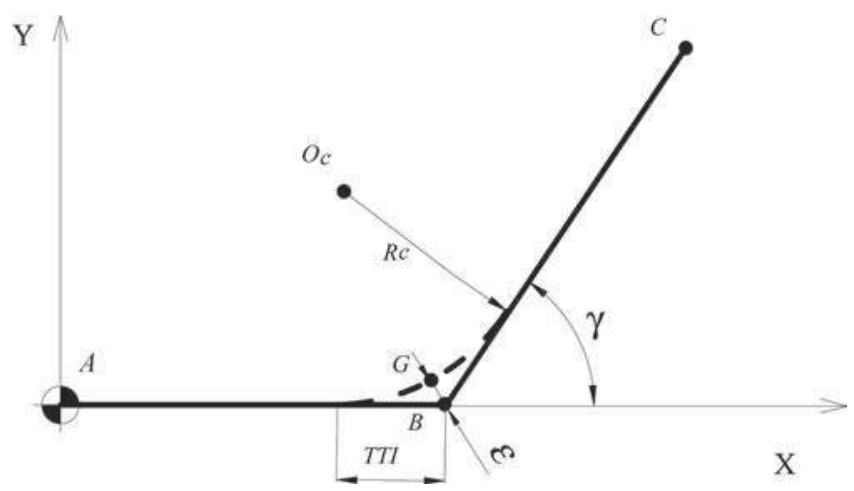

FIGURE 5 Modeling of a fillet radius of a discontinuity in tangency. 
First, linear-circular interpolation will be studied. In this case, the tool path is represented by a linear contour $(\mathrm{BC})$ and a circular contour (CD: circle $C$, radius $R$ and center $O$ ) (as shown in Figure 6).

The coordinates of point $\mathrm{D}$ are given by:

$$
X_{D}=2 R \sin \frac{\theta}{2} \cos \kappa+X_{C} \quad Y_{D}=2 R \sin \frac{\theta}{2} \sin \kappa+Y_{C}
$$

Where: $X_{C}$ and $Y_{C}$ are the point $C$ coordinates.

The tool path presents a discontinuity in tangency located at connection between linear (BC) and circular contour (as shown in Figure 6). This discontinuity in tangency has been replaced by discontinuity in curvature by adding an arc with a center $O_{c}$, with a fillet radius $R_{c}$ calculated in relation to imposed error $\varepsilon$.

First, the angles $\theta$ and $\kappa$ are determined using Equation (5). Then, the angle $\gamma$ is calculated from Equation (1).

The fillet radius, which depends on the imposed error $\varepsilon$ (as shown in Figure 6). It is given by:

$$
\varepsilon=\sqrt{\left(X_{B}-X_{G}\right)^{2}+\left(Y_{B}-Y_{G}\right)^{2}}
$$

The equation of the circular interpolation in arc $\mathrm{CD}$ is:

$$
\left(X-X_{O}\right)^{2}+\left(Y-Y_{O}\right)^{2}=R^{2}
$$

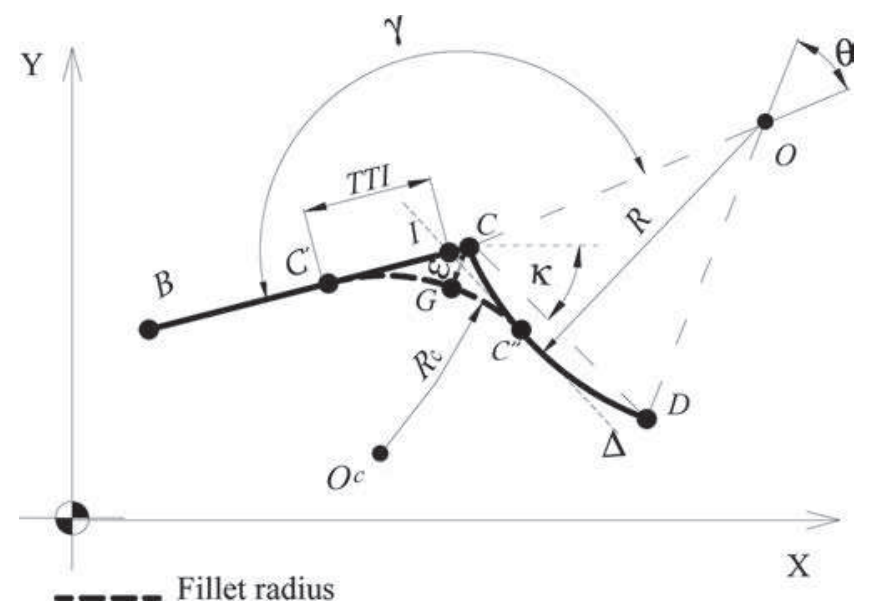

FIGURE 6 Fillet radius between linear-circular contour. 
Coordinates of the point $O_{c}$ and the radius $R_{c}$ are calculated by:

$$
\left\{\begin{array}{l}
\left(X_{C}-X_{O_{c}}\right)^{2}+\left(Y_{C}-Y_{O_{c}}\right)^{2}=\left(\varepsilon+R_{c}\right)^{2} \\
\frac{\left|\frac{Y_{C}-Y_{B}}{X_{C}-X_{B}} X_{O_{c}}-Y_{O_{c}}+\frac{Y_{B} X_{C}-Y_{C} X_{B}}{X_{C}-X_{B}}\right|}{\sqrt{1+\left(\frac{Y_{C}-Y_{B}}{X_{C}-X_{B}}\right)^{2}}}=R_{c} \\
\left(X_{O}-X_{O_{c}}\right)^{2}+\left(Y_{O}-Y_{O_{c}}\right)^{2}=\left(R+R_{c}\right)^{2}
\end{array}\right.
$$

$T T I$ is calculated in relation to $\varepsilon$. It is introduced in the zone from which or to which the block transition is rounded (as shown in Figure 6) when $T T I=I C^{\prime}=I C^{\prime \prime}$.

With: $I$ is the intersection between $\Delta$ and the line BC, $\Delta$ is the tangent to the circle $C$ at point $C^{\prime \prime}$, and the points $C^{\prime}$ and $C^{\prime \prime}$ have the coordinates:

$$
\left\{\begin{array}{l}
\left(X_{C^{\prime}}-X_{O_{c}}\right)^{2}+\left(Y_{C^{\prime}}-Y_{O_{c}}\right)^{2}=R_{c}^{2} \\
\frac{Y_{C}-Y_{B}}{X_{C}-X_{B}} X_{D}-Y_{D}+\frac{Y_{B} X_{C}-Y_{C} X_{B}}{X_{C}-X_{B}}=0 \\
\left(X_{C^{\prime \prime}}-X_{O_{c}}\right)^{2}+\left(Y_{C^{\prime \prime}}-Y_{O_{c}}\right)^{2}=R_{c}^{2} \\
\left(X_{C^{\prime \prime}}-X_{O}\right)^{2}+\left(Y_{C^{\prime \prime}}-Y_{O}\right)^{2}=R^{2}
\end{array}\right.
$$

Coordinates of point I may be calculated by:

$$
\left\{\begin{array}{l}
\left(X_{C^{\prime}}-X_{I}\right)^{2}+\left(Y_{C^{\prime}}-Y_{I}\right)^{2}=\left(X_{C^{\prime \prime}}-X_{I}\right)^{2}+\left(Y_{C^{\prime \prime}}-Y_{I}\right)^{2} \\
\frac{Y_{C}-Y_{B}}{X_{C}-X_{B}} X_{I}-Y_{I}+\frac{Y_{B} X_{C}-Y_{C} X_{B}}{X_{C}-X_{B}}=0
\end{array}\right.
$$

The value of (TTI) is given by:

$$
T T I=\sqrt{\left(X_{C^{\prime}}-X_{I}\right)^{2}+\left(Y_{C^{\prime}}-Y_{I}\right)^{2}}
$$

Figure 7 shows a path presented a discontinuity in tangency located at connection between linear and circular contour with the angle of orientation $\gamma<90^{\circ}$ :

$R_{c}, X_{O c}$, and $Y_{O c}$ are calculated as follows:

$$
\left\{\begin{array}{l}
\left(X_{C}-X_{O_{c}}\right)^{2}+\left(Y_{C}-Y_{O_{c}}\right)^{2}=\left(\varepsilon+R_{c}\right)^{2} \\
\frac{\left|\frac{Y_{C}-Y_{B}}{X_{C}-X_{B}} X_{O_{c}}-Y_{O_{c}}+\frac{Y_{B} X_{C}-Y_{C} X_{B}}{X_{C}-X_{B}}\right|}{\sqrt{1+\left(\frac{Y_{C}-Y_{B}}{X_{C}-X_{B}}\right)^{2}}}=R_{c} \\
\left(X_{O}-X_{O_{c}}\right)^{2}+\left(Y_{O}-Y_{O_{c}}\right)^{2}=\left(R-R_{c}\right)^{2}
\end{array}\right.
$$




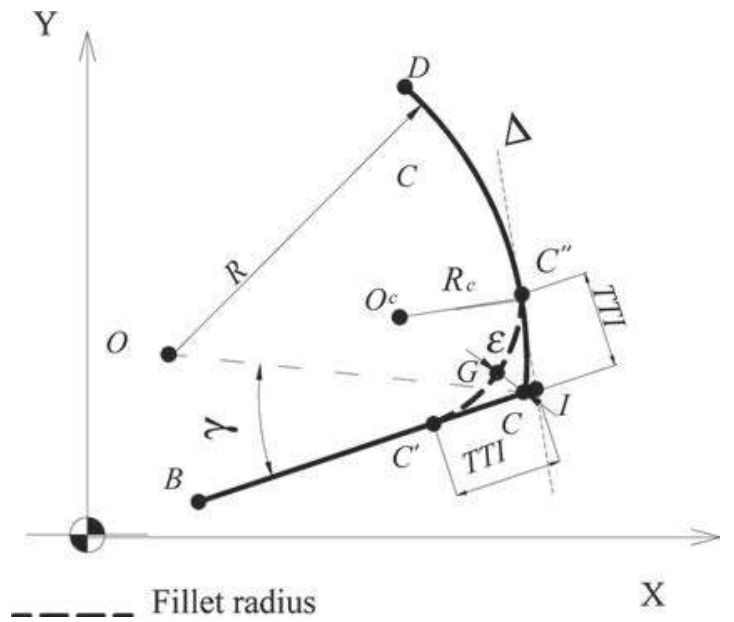

FIGURE 7 Fillet radius between linear-circular contours.

Second, circular-circular interpolation will be detailed (as shown in Figure 8). So, the tool path was represented by two arcs: (CD: circle $\mathrm{C}_{1}$, radius $R_{1}$ and center $O_{1}$ ) and (DE: circle $\mathrm{C}_{2}$, radius $R_{2}$ and center $O_{2}$ ).

The coordinates of point $\mathrm{E}$ are given by:

$$
X_{E}=2 R_{2} \sin \frac{\theta_{2}}{2} \cos \kappa_{2}+X_{D} \quad Y_{E}=2 R_{2} \sin \frac{\theta_{2}}{2} \sin \kappa_{2}+Y_{D}
$$

$X_{D}$ and $Y_{D}$ are the point $\mathrm{D}$ coordinates, they are given by:

$$
X_{D}=2 R_{1} \sin , \frac{\theta_{1}}{2} \cos \kappa_{1}+X_{C} \quad Y_{D}=2 R_{1} \sin \frac{\theta_{1}}{2} \sin \kappa_{1}+Y_{C}
$$

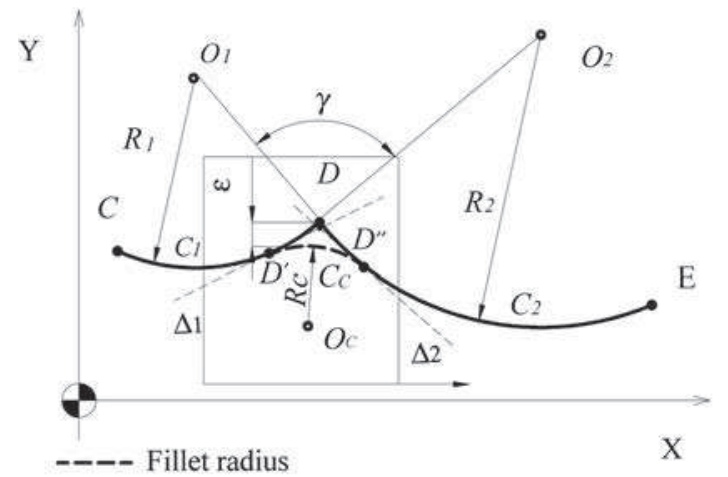

(a)

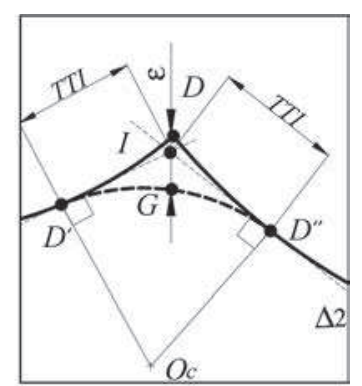

Zoom in the discontinuity

(b)

FIGURE 8 Fillet radius between circular-circular interpolations. 
Where: $X_{C}$ and $Y_{C}$ are the point $\mathrm{C}$ coordinates.

First, the angles $\theta_{1}, \theta_{2}, \kappa_{1}$ and $\kappa_{2}$ are determined using Equations (12) and (13) and then the angle $\gamma$ is resolute from Equation (2).

The fillet radius, which depends on the imposed error $\varepsilon$, is given by:

$$
\varepsilon=\sqrt{\left(X_{D}-X_{G}\right)^{2}+\left(Y_{D}-Y_{G}\right)^{2}}
$$

The equation of the circular interpolation in arc $\mathrm{CD}$ is:

$$
\left(X-X_{O_{1}}\right)^{2}+\left(Y-Y_{O_{1}}\right)^{2}=R_{1}^{2}
$$

The equation of the circular interpolation in arc DE is:

$$
\left(X-X_{O_{2}}\right)^{2}+\left(Y-Y_{O_{2}}\right)^{2}=R_{2}^{2}
$$

The coordinates of the point $O_{c}$ and the radius $R_{c}$ are calculated by:

$$
\left\{\begin{array}{l}
\left(X_{O_{c}}-X_{O 1}\right)^{2}+\left(Y_{O_{c}}-Y_{O_{1}}\right)^{2}=\left(R_{1}+R_{c}\right)^{2} \\
\left(X_{O_{c}}-X_{O_{2}}\right)^{2}+\left(Y_{O_{c}}-Y_{O_{2}}\right)^{2}=\left(R_{2}+R_{c}\right)^{2} \\
\left(X_{O_{c}}-X_{D}\right)^{2}+\left(Y_{O_{c}}-Y_{D}\right)^{2}=\left(\varepsilon+R_{c}\right)^{2}
\end{array}\right.
$$

With: $I$ is the intersection between $\Delta_{1}$ and $\Delta_{2}, \Delta_{1}$ is the tangent to the circle $C_{1}$ at point $D^{\prime}$ and $\Delta_{2}$ is the tangent to the circle $C_{2}$ at point $D^{\prime \prime}$.

The points $D^{\prime}$ belongs to circles $C_{c}$ and $C_{1}$ and $D^{\prime \prime}$ belongs to circles $C_{c}$ and $C_{2}$. Thus the coordinates of $D^{\prime}$ and $D^{\prime \prime}$ are calculated using the circle equations.

The coordinates of point $I$ may be calculated by:

$$
\left\{\begin{array}{l}
\left(X_{D^{\prime}}-X_{I}\right)^{2}+\left(Y_{D^{\prime}}-Y_{I}\right)^{2}=\left(X_{D^{\prime \prime}}-X_{I}\right)^{2}+\left(Y_{D^{\prime \prime}}-Y_{I}\right)^{2} \\
-\frac{X_{O_{1}}-X_{D^{\prime}}}{Y_{O_{1}}-Y_{D^{\prime}}} X_{I}-Y_{I}+\frac{X_{O_{1}} X_{D^{\prime}}+Y_{O_{1}} Y_{D^{\prime}}-X_{D^{\prime}}^{2}-Y_{D^{\prime}}^{2}}{Y_{O_{1}}-Y_{D^{\prime}}}=0
\end{array}\right.
$$

The value of TTI is given by:

$$
T T I=\sqrt{\left(X_{D^{\prime}}-X_{I}\right)^{2}+\left(Y_{D^{\prime}}-Y_{I}\right)^{2}}
$$

In Siemens NCU, the $T T I$ value must not exceed $0.5 \mathrm{~mm}$. If the resulting theoretical value exceeds $0.5 \mathrm{~mm}$, the radius $R_{c}$ must be introduced in the program with a circular interpolation between $D^{\prime}$ and $D^{\prime \prime}$. This Circle arc inserted with circular interpolation (G02 and G03) or by a modal instruction, RNDM or a not modal instruction, RND. 


\section{FEED RATE MODELING}

Figure 9 depicts the correspondence between the tool path and the feed rate profile.

The tool path is locally modified at connection between linear-circular by adding circle arcs contours to remove tangential discontinuity.

For motion along the tool path, the value of jerk is constant. So, the acceleration has trapezoidal profiles (Erkorkmaz and Altintas, 2001; Pessoles et al., 2010). The phase of acceleration is composed to 3 zones (as shown in Figure 10).

The expression of the acceleration time is:

$$
T_{a c c}=2 T_{J_{m}}+T_{A_{m}}
$$

$T_{J_{m}}$ and $T_{A_{m}}$, respectively, present the time when the feed rate is controlled by the maximum jerk and the time when the feed rate is controlled by the maximum acceleration.

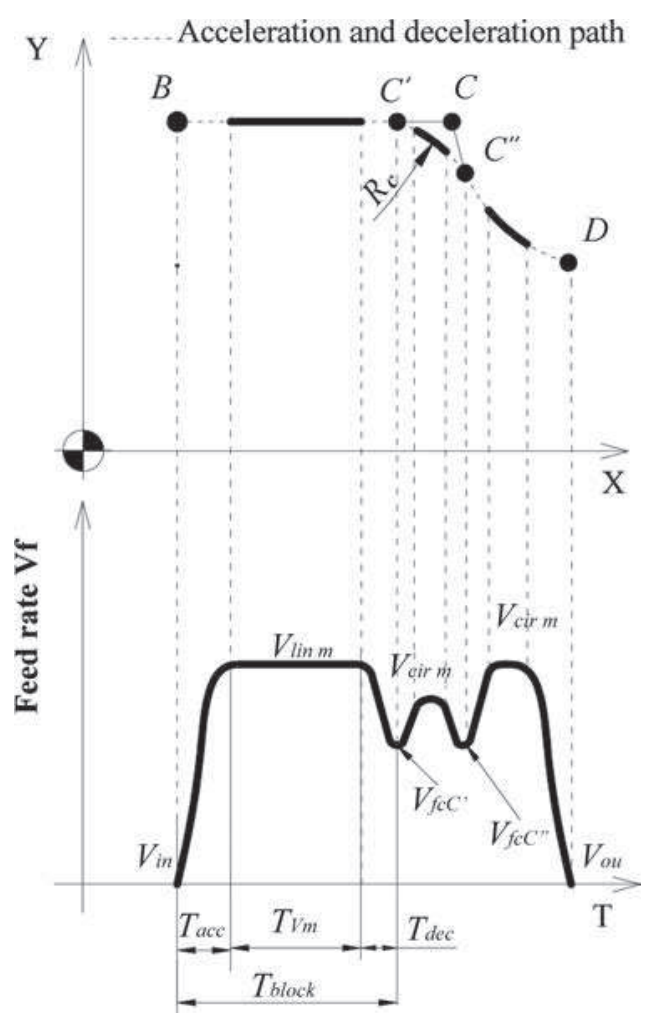

FIGURE 9 Feed rate profile for the linear-circular contour. 


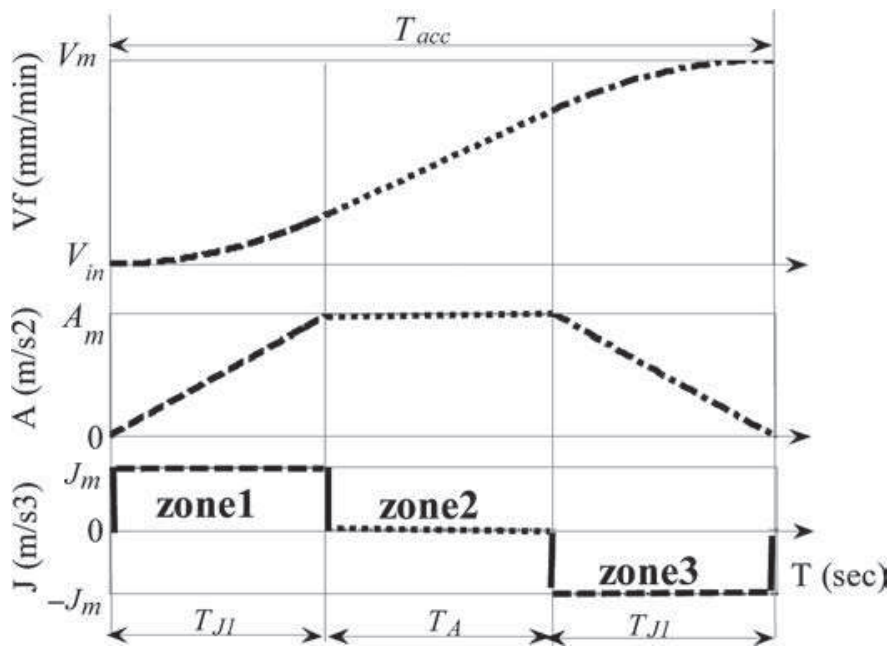

FIGURE 10 Acceleration phase.

The profiles generated in the deceleration phase are totally symmetric to acceleration phase. Based on the work of (Erkorkmaz and Altintas, $2001)$, the duration of each phase $\left(T_{a c c}, T_{V m}, T_{d e c}\right)$ must be calculated according to the geometric and kinematic constraints. MATLAB $\mathbb{C}$ software is used for developing a feed rate simulator.

\section{Calculation of a Circular and Linear Interpolation}

According to Pateloup (2005), the feed rate is related to three types of parameters: adjustments and capacity of NCU, the NC programs and the capacities of the axes.

Feed rate for the linear interpolation

In linear interpolation:

$$
A_{t}=\frac{d V_{f}(T)}{d T} \quad \text { and } \quad A_{n}=0
$$

The used kinematical parameters are limited by the less dynamic axis ${ }^{2}$ (Dugas, 2002):

$$
\begin{aligned}
V_{a} & =\min \left(\frac{V_{p \mathrm{~m} X}}{|\cos \alpha|}, \frac{V_{\mathrm{m} Y}}{|\sin \alpha|}\right) ; \quad A_{t}=\min \left(\frac{A_{\mathrm{m} X}}{|\cos \alpha|}, \frac{A_{\mathrm{m} Y}}{|\sin \alpha|}\right) ; \\
J_{m} & =\min \left(\frac{J_{\mathrm{m} X}}{|\cos \alpha|}, \frac{J_{\mathrm{m} Y}}{|\sin \alpha|}\right)
\end{aligned}
$$


$\alpha, V_{m X}, V_{m Y}, A_{m X}, A_{m Y}, J_{m X}$, and $J_{m Y}$ respectively are the inclination angular, the maximum feed rate for the $\mathrm{X}$-axis, the maximum feed rate for the $\mathrm{Y}$-axis, the maximum acceleration for the $\mathrm{X}$-axis, the maximum acceleration for the Y-axis, the maximum jerk for the $\mathrm{X}$-axis and the maximum jerk for the Y-axis.

The feed rate limited by the interpolation cycle time $t_{c y}$ is:

$$
V_{t c y}=\frac{L_{l i n}}{T_{c y}}
$$

The feed rate imposed by the tool path length $V_{L_{b}}$ : is the case when the sum of the acceleration and deceleration length $\left(L_{a c c}\right.$ and $\left.L_{d e c}\right)$ is higher to $L_{\text {lin }}$. So, the machine never finds the sufficient stroke to reach the maximum feed rate.

The feed rate in the linear interpolation is:

$$
V_{\text {linm }}=\min \left(V_{a}, V_{\text {tcy }}, V_{L_{b}}, V_{f p r o g}\right)
$$

\section{Feed Rate for the Circular Interpolation}

In circular interpolation, the acceleration has two components: tangential acceleration $A_{t}$, and a normal acceleration $A_{n}$.

$$
A_{t}=\frac{d V_{f}(T)}{d T} \quad A_{n}=\frac{V_{f}^{2}(T)}{R}
$$

The less dynamic axis requires its capabilities during kinematic displacement when more than one axis has to be used. The optimum solution is to use an axis to its maximum capacity, or to define the following limitation (Tapie et al., 2007):

$$
\begin{aligned}
& V_{a}=\min \left(\frac{V_{\mathrm{m} X}}{\left|\cos \alpha_{p}\right|}, \frac{V_{\mathrm{m} Y}}{\left|\sin \alpha_{P}\right|}\right) ; \quad A_{n}=\min \left(\frac{A_{\mathrm{m} X}}{\left|\cos \alpha_{P}\right|}, \frac{A_{\mathrm{m} Y}}{\left|\sin \alpha_{P}\right|}\right) ; \\
& A_{t}=\min \left(\frac{A_{\mathrm{m} X}}{\left|\cos \alpha_{e}\right|}, \frac{A_{\mathrm{m} Y}}{\left|\sin \alpha_{e}\right|}\right) J_{t}=\min \left(\frac{J_{\mathrm{m} X}}{\left|\cos \alpha_{P}\right|}, \frac{J_{\mathrm{m} Y}}{\left|\sin \alpha_{P}\right|}\right)
\end{aligned}
$$

With $\alpha_{p} \in\left[\alpha_{e}, \alpha_{s}\right] ; \alpha_{s}-\alpha_{e}=\theta$ and $\alpha_{e}=\arccos \left(\frac{\left|X_{O 1}-X_{C}\right|}{R}\right)$

$\alpha_{p}, \alpha_{e}$, and $\alpha_{s}$, respectively, are the angular position, the input angle and the output angle.

For small radius values, the feed rate will be limited by the NCU. 
The feed rate $V_{t c y}$, limited by the interpolation cycle time $t_{c y}$, is:

$$
V_{t c y}=\frac{R \theta}{t_{c y}}=\frac{L_{c i r}}{t_{c y}}
$$

When the stationary feed rate is reached, the two corresponding parameters are normal acceleration $A_{n}$ and tangential jerk $J_{m}$.

The expression of the jerk is:

$$
\vec{J}=\frac{d \vec{A}}{d T}=\frac{d A}{d T} \vec{N}+A \frac{d \vec{N}}{d T} \Rightarrow J_{t}=\frac{V_{f}^{3}(T)}{R^{2}}
$$

When we use the limitation of the normal acceleration, the feed rate is (Dugas, 2002):

$$
V_{A n}=\sqrt{R A_{n}}
$$

When we use the limitation of the tangential jerk, the feed rate is deduced from Equation (4) (Dugas, 2002):

$$
V_{J t}=\sqrt[3]{J_{t} R^{2}}
$$

The feed rate in the circular interpolation is:

$$
V_{\text {cirm }}=\min \left(V_{a} ; V_{\text {fprog }} ; V_{J t} ; V_{A n} ; V_{t c y} ; V_{L_{b}}\right)
$$

\section{Calculation of the Feed Rate of Crossing on a Discontinuity in Curvature}

At the time of a discontinuity in tangency or in curvature, numerical control unit slows down in order to respect the maximum values of acceleration and Jerk for each axis (Figure 11).

Discontinuity in curvature between two circular interpolations (point $C^{\prime}$ ).

The feed rate for a discontinuity in curvature between two circle arcs with different radius values is proposed in (Pateloup, 2005):

$$
V_{f c}=\sqrt{\frac{R_{1} R_{2} J_{t} \delta t}{R_{1}+R_{2}}}
$$

Discontinuity in curvature between a linear and circular interpolation (point $C^{\prime}$ ) 


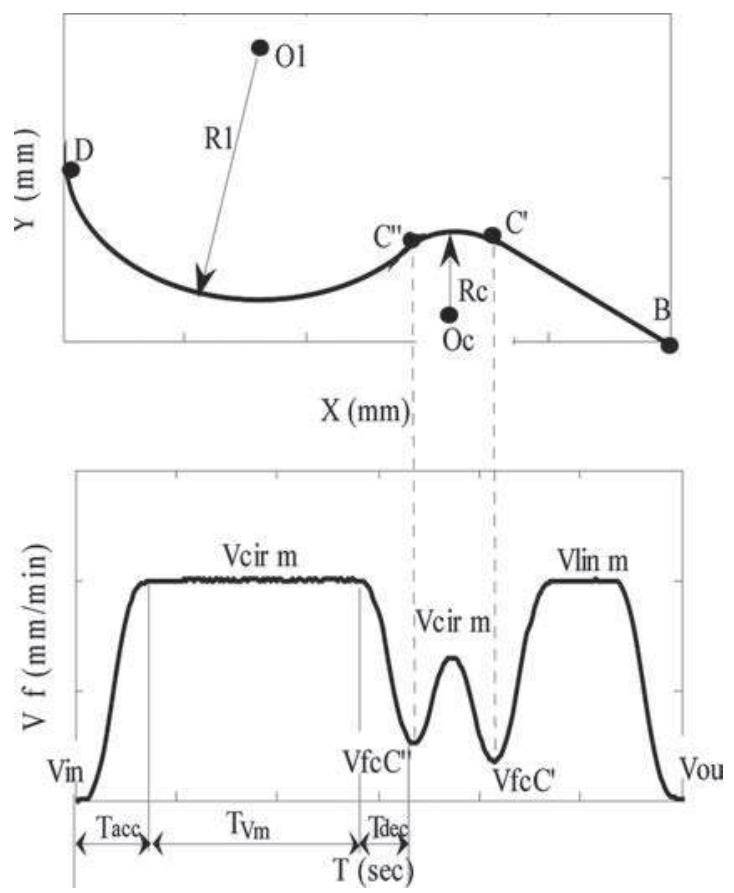

FIGURE 11 Discontinuity in curvature (continuity in tangency).

For a discontinuity in curvature, the federate between a linear and circular interpolation is (Pateloup et al., 2004):

$$
V_{f c}=\sqrt{R C} \text { et } C=J_{t} \delta t
$$

Thus, for a given fillet radius, the feed rate at the discontinuity will be limited:

$$
V_{f c m}=\min \left(V_{f c} ; V_{f p r o g} ; V_{J t} ; V_{A n} ; V_{t c y} ; V_{L_{b}}\right)
$$

\section{Calculation of the Feed Rate of Crossing on a Discontinuity in Tangency}

In the transition of a discontinuity in tangency, the derivative of the tangent to the tool path $\frac{d(T)}{d s}$ is not defined. Consequently, the crossing feed rate, $V_{f c}$, had to be nullified to avoid the infinite acceleration.

The transition that had a null feed rate at crossing on a discontinuity was a manner of solving the problem. This implied a stop of cutting process, brand of the part and an increase in the machining cycle time. 
Another solution is to authorize an error $(\varepsilon)$ between the programmed trajectory and the real trajectory to obtain a non-null feed rate of crossing. In this case, the tool does not pass along the point of discontinuity as said before.

\section{Algorithm}

The modeling steps are represented in the following diagram shown on Figure 12. The modeling steps are as follows:

- Determination of the angle $\gamma$ by using the points coordinates in order to identify the type of discontinuity.

- Calculation of the fillet radius $\left(R_{c}\right)$, if it is a discontinuity in tangency.

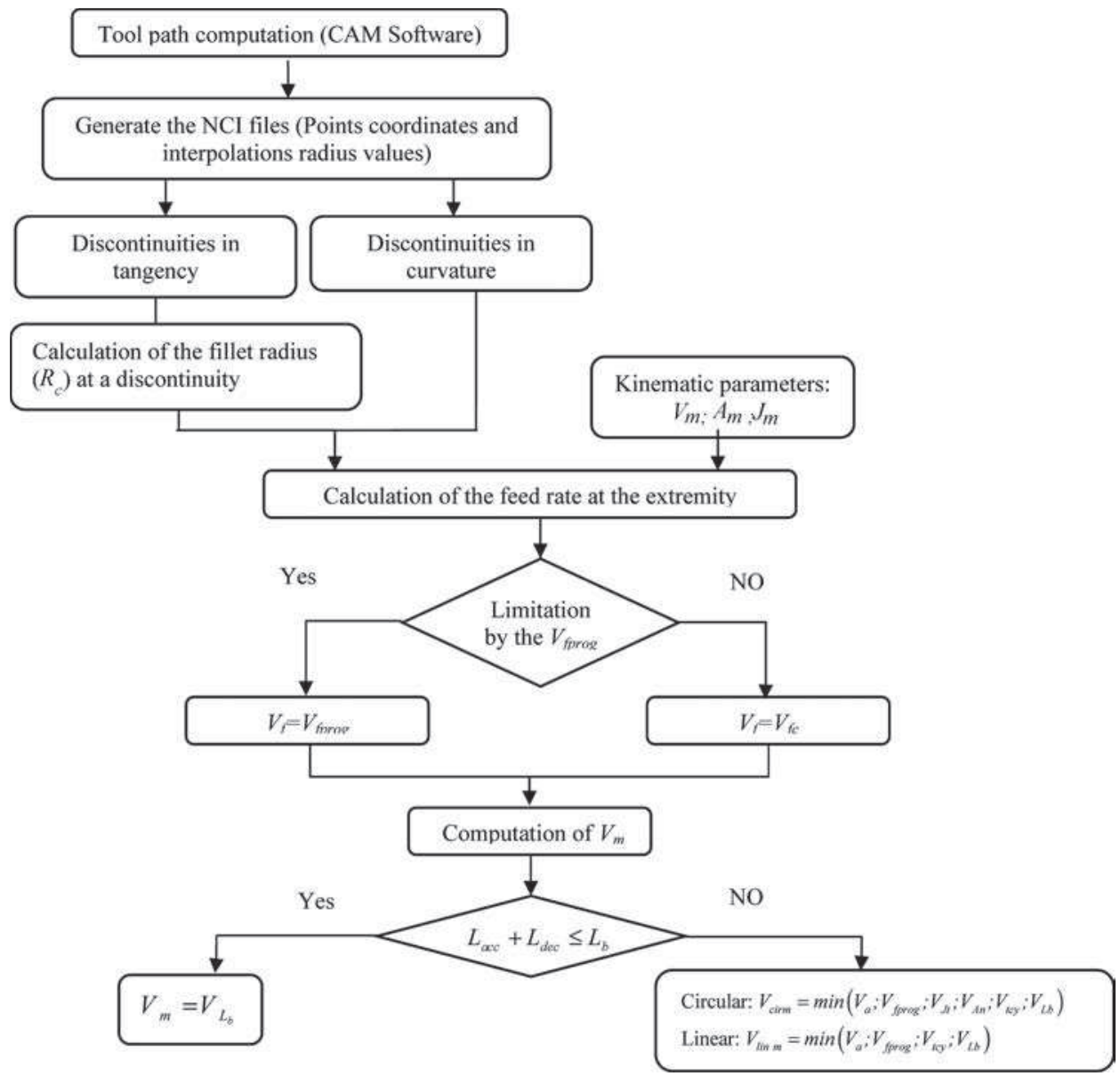

FIGURE 12 Recursive algorithm for estimating feed rate. 
- Calculation of the feed rate at the extremity using Equations (26) and (27).

- Computation of the maximum feed rate $V_{\text {lin } m}$ and $V_{\text {cir } m}$.

- Calculation of the duration of each phase $T\left(T_{a c c}, T_{d e c}, T_{V m}\right)$ for each block.

- Plot the evolution of feed rate in function of time using MATLAB (C) software.

\section{MACHINING CYCLE TIME MODELING}

The machining cycle time is expressed:

$$
T_{c \bmod }=\sum_{k=1}^{N}\left(T_{V_{\mathrm{m}}}(k)+T_{a c c}(k)+T_{d e c}(k)\right)
$$

$T_{V m}$ is the total time along the distance of the tool path with maximum feed rate $V_{m}, T_{a c c}$ is the acceleration time and $T_{d e c}$ is the deceleration time during the $k$ th interpolation.

$N$ is the total number of interpolations that constitute the trajectory.

The total time $T_{V m}$ is given by the following expression:

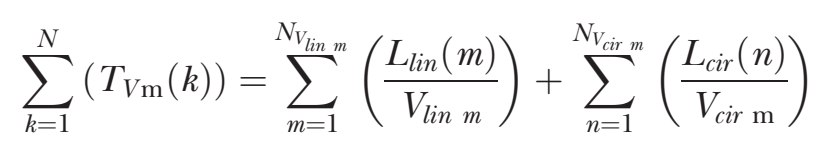

With $N_{V_{\text {linm }}}, N_{V_{\text {cirm }}}, L_{\text {lin }}$ and $L_{c i r}$ are, respectively, the number of interpolations for which feed rate reached the maximum feed rate $V_{\text {lin } m}$, the number of circular interpolation for which feed rate could reach the maximum feed rate $V_{\text {cir } \mathrm{m}}$, the length of feed rate reached the maximum feed rate $V_{\text {lin } m}$ in the linear interpolation number $m$ and the length of feed rate reached the maximum feed rate $V_{c i r \mathrm{~m}}$ in the circular interpolation number $n$.

\section{EXPERIMENTAL STUDY}

To validate the proposed models, an experimental study was conducted. In particular, feed rate evolution for three values of the orientation angle $\gamma$ between linear and circular interpolation was tested and cycle time for a machined die was registered. This experimental study was carried out on a high speed machine (Huron $\mathrm{K} \times 10$ ). Its characteristics are given in Table 1.

The continuous path mode with the tangential displacement mode (G641) and the "soft" acceleration (Sinumerik, 2006) were integrated. 
TABLE 1 The Characteristics of the Machine

\begin{tabular}{lc}
\hline Huron K $\times 10$ & \\
\hline Spindle & \\
Spindle speed & $100-24000 \mathrm{rev} / \mathrm{min}$ \\
Maximum Power & $20 \mathrm{~kW}$ \\
Axis capacity & \\
Maximum fast speed X Y & $30 \mathrm{~m} / \mathrm{min}$ \\
Maximum fast speed Z & $18 \mathrm{~m} / \mathrm{min}$ \\
Feed rate: & $10 \mathrm{~m} / \mathrm{min}$ \\
Maximum acceleration & $3 \mathrm{~m} / \mathrm{s}^{2}$ \\
MaximumJerk & $50 \mathrm{~m} / \mathrm{s}^{3}$ \\
NCU & \\
Design & \\
Acceleration mode & Siemens $840 \mathrm{D}$ \\
Tangential displacement mode & Soft \\
Look ahead & G641 \\
Interpolation cycle time & $100 \mathrm{blocs}$ \\
\hline
\end{tabular}

\section{Elementary Tests}

In this part, three tests are designed on the linear-circular interpolation (Table 2) that is presented on Figure 13. The first test enables to validate the simulation method for the case of the continuity in tangency. The second one permits to validate the modeling of feed rate at the discontinuity in tangency point. The last test confirms the modeling of feed rate for another value of orientation angle $\gamma$ and imposed error.

Table 2 presents the geometry and kinematic parameters used.

Based on a geometry presented in the Test 1 (as shown in Table 2), the feed rate variation to crossing in the discontinuity in curvature (continuity in tangency) is calculated (as shown in Figure 14).

Test 2 presents the geometrical parameters of the path with discontinuity in tangency. This discontinuity is eliminated by adding a circle arc,

TABLE 2 Geometric Parameters

\begin{tabular}{|c|c|c|c|c|c|c|c|c|c|c|c|c|}
\hline & \multicolumn{12}{|c|}{ Discontinuity in $\mathrm{C}$} \\
\hline & & \multicolumn{3}{|c|}{$\begin{array}{c}\text { Points } \\
\text { coordinates }\end{array}$} & \multirow{2}{*}{$\begin{array}{c}R_{1} \\
(\mathrm{~mm})\end{array}$} & \multirow{2}{*}{$\begin{array}{l}\theta_{1} \\
\left({ }^{\circ}\right)\end{array}$} & \multirow{2}{*}{$\begin{array}{l}\gamma \\
\left({ }^{\circ}\right)\end{array}$} & \multirow{2}{*}{$\begin{array}{c}\text { Type of } \\
\text { discontinuity }\end{array}$} & \multirow{2}{*}{$\begin{array}{c}\varepsilon \\
(\mathrm{mm})\end{array}$} & \multirow{2}{*}{$\begin{array}{c}R c \\
(\mathrm{~mm})\end{array}$} & \multirow{2}{*}{$\begin{array}{c}\text { TTI } \\
(\mathrm{mm})\end{array}$} & \multirow{2}{*}{$\begin{array}{c}V_{\text {fprog }} \\
(\mathrm{mm} / \mathrm{min})\end{array}$} \\
\hline & & $B$ & $C$ & $D$ & & & & & & & & \\
\hline \multirow[t]{2}{*}{ Test 1} & $\mathrm{X}$ & 10 & 110 & 153.3 & 50 & 60 & 90 & In curvature & - & - & - & 10000 \\
\hline & $\mathrm{Y}$ & 20 & 20 & 45 & & & & & & & & \\
\hline \multirow[t]{2}{*}{ Test 2} & $\mathrm{X}$ & 10 & 110 & 160 & 50 & 60 & 120 & In tangency & 0.07 & 1.88 & 0.5 & 10000 \\
\hline & $\mathrm{Y}$ & 20 & 20 & 20 & & & & & & & & \\
\hline \multirow[t]{2}{*}{ Test 3} & $\mathrm{X}$ & 10 & 61.42 & 74.81 & 50 & 60 & 180 & In tangency & 1.55 & 4 & - & 10000 \\
\hline & $\mathrm{Y}$ & 20 & 20 & 95.96 & & & & & & & & \\
\hline
\end{tabular}




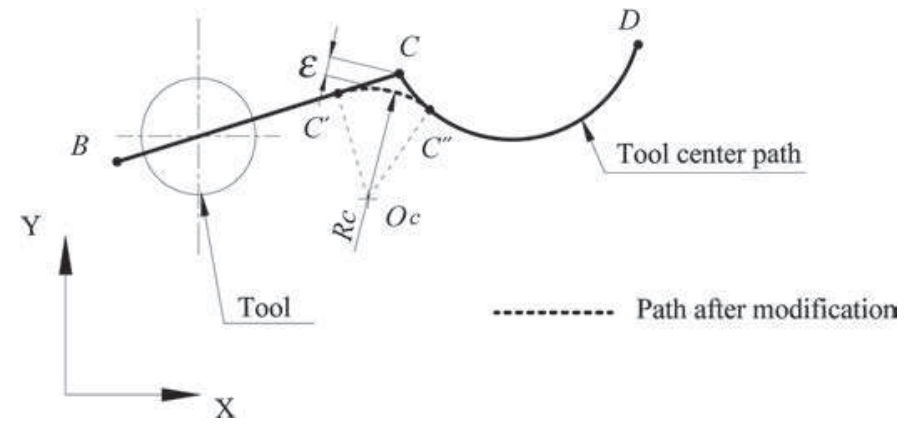

FIGURE 13 Tool path geometry.

which is function of the TTI. Figure 15 presents the theoretical and the experimental feed rate variation for this trajectory.

Test 3 is like the latter, although the circle arc is introduced in the program with RND function (as shown in Figure 16).

At discontinuity (point $C$ ), it is noted that the machine slows down immediately. In the crossing of a discontinuity, the machine adopted a maximum speed in relation to its capacities, the type of discontinuity and the imposed error $\varepsilon$.

A good correlation has been found between experimental and theoretical results. Table 3 presents the error between measured feed rate on the machine and calculated feed rate by the model for the various tests presented in Table 2. It is noted that the error between theoretical and experiments feed rate in the transition ranging from 1 to $10 \%$, while the error on the total machining cycle time is less than $3.6 \%$.

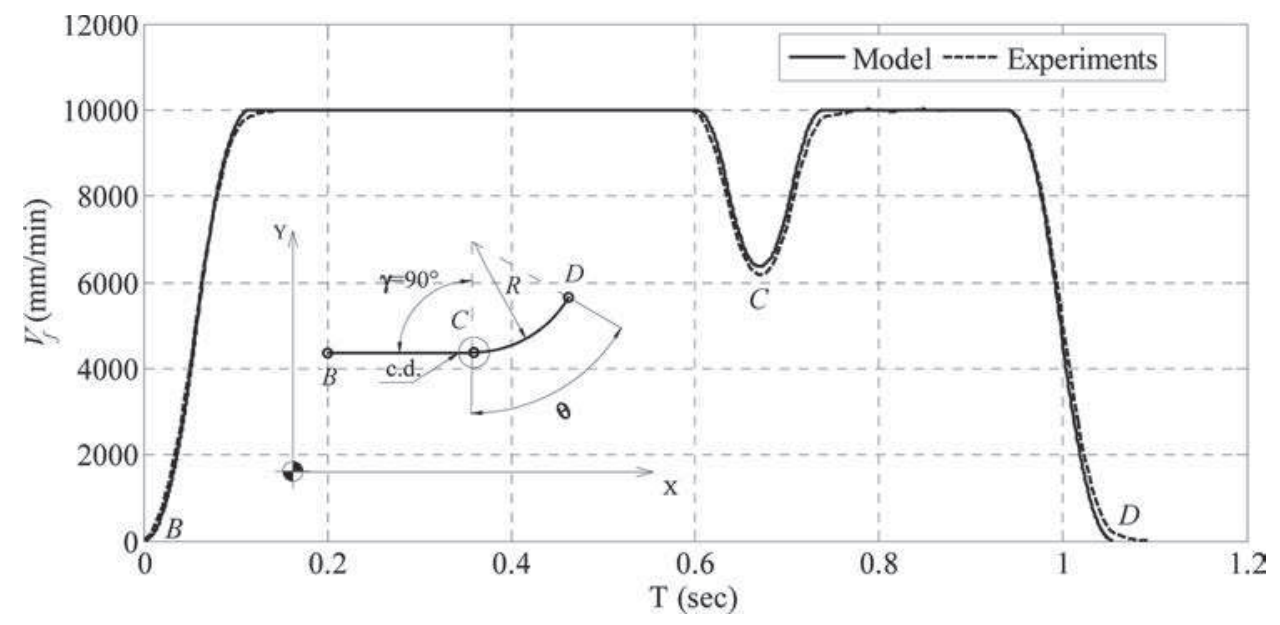

FIGURE 14 Theoretical and experimental variation of feed rate. 


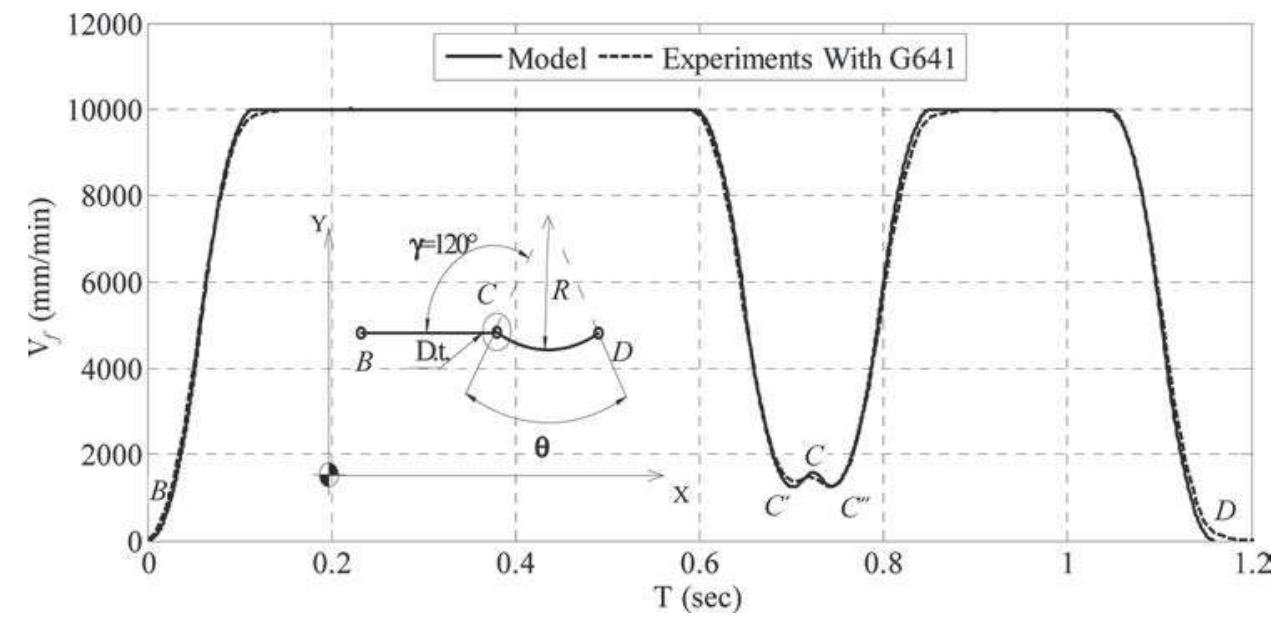

FIGURE 15 Theoretical and experimental variation of feed rate; $T T I=0.5 \mathrm{~mm}$.

\section{Industrial Application}

The procedure of determining the feed rate was applied to a machined die of the Tunisian manufacture SIAF (Figure 17 and Figure 18). The final HSM configuration adopted for this application integrates the continuous path mode with the tangential displacement mode (G641 with $T T I=0.05 \mathrm{~mm}$ ), the "soft" acceleration mode and the tolerance limits is $0.02 \mathrm{~mm}$. The CAM software is used to generate the trajectory of the tool as well as approximate times of the various operations. The cutting parameters are the following:

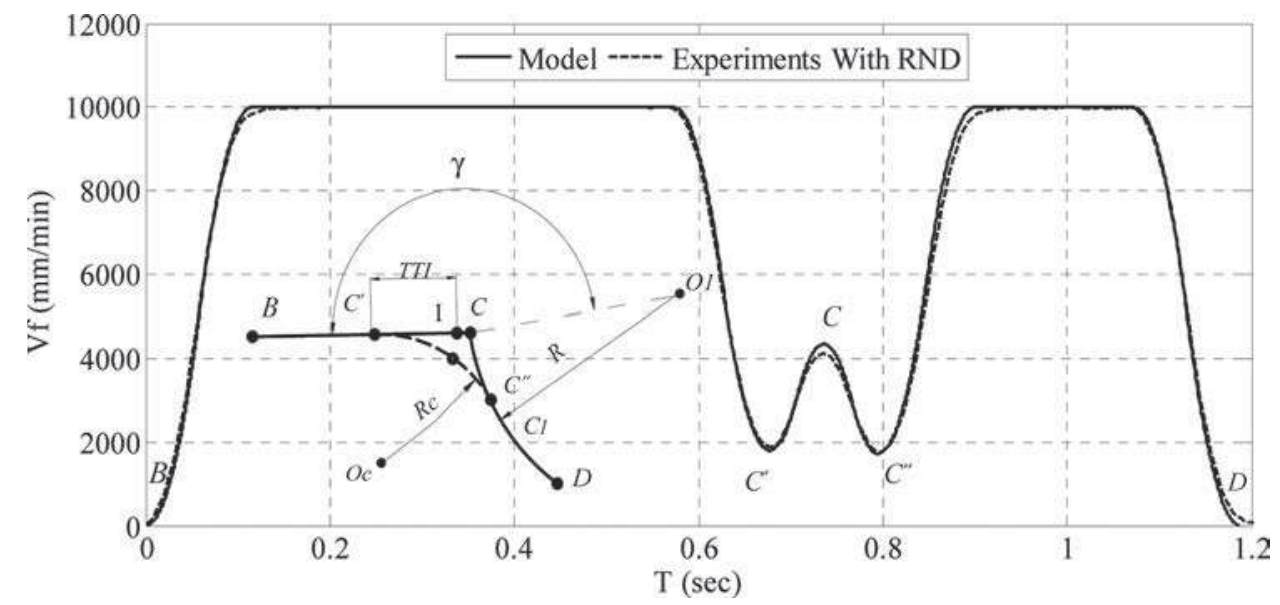

FIGURE 16 Theoretical and experimental variation of feed rate; $R_{c}=4 \mathrm{~mm}$. 
TABLE 3 Error Calculated on the Feed Rate at the Point of Discontinuity

\begin{tabular}{|c|c|c|c|c|c|c|c|}
\hline \multirow[b]{2}{*}{ Test } & \multirow[b]{2}{*}{ Points } & \multicolumn{3}{|c|}{ Feed rate in the transition $(\mathrm{mm} / \mathrm{min})$} & \multicolumn{3}{|c|}{ Machining cycle time (s) } \\
\hline & & Model & Experiments & Error $(\%)$ & Model & Experiments & Error $(\%)$ \\
\hline 1 & $C$ & 6364 & 6173 & 3 & 1.05 & 1.09 & 3.6 \\
\hline \multirow[t]{3}{*}{2} & $C^{\prime}$ & 1234 & 1371 & 9.9 & 1.16 & 1.2 & 3.3 \\
\hline & $C$ & 1571 & 1479 & 6.2 & & & \\
\hline & $C^{\prime \prime}$ & 1211 & 1242 & 2.4 & & & \\
\hline \multirow[t]{3}{*}{4} & $C^{\prime}$ & 1800 & 1887 & 4.6 & 1.18 & 1.22 & 3.2 \\
\hline & $C$ & 4352 & 4125 & 5.5 & & & \\
\hline & $C^{\prime \prime}$ & 1732 & 1762 & 1.7 & & & \\
\hline
\end{tabular}

Roughing operation:

- Tool path strategy: Spiral parallel.

- $V_{\text {fprog }}=10,000 \mathrm{~mm} / \mathrm{min}$.

- The diameter of tool $d_{\text {tool }}=16 \mathrm{~mm}$.

- The radial depth of cut $a_{e}=0.9 d_{t o o l} \mathrm{~mm}$.

- The axial depth of cut $a p=0.3 \mathrm{~mm}$.

- Spindle speed, $\mathrm{N}=3800 \mathrm{rev} / \mathrm{min}$.

The tool path presented in Figure 19 includes the various cases of connection between linear and circular interpolations in different combinations.

Table 4 presents the analytical solutions of the orientation angle $\gamma$ and fillet radius $R c$ at some points placed on the tool path presented in

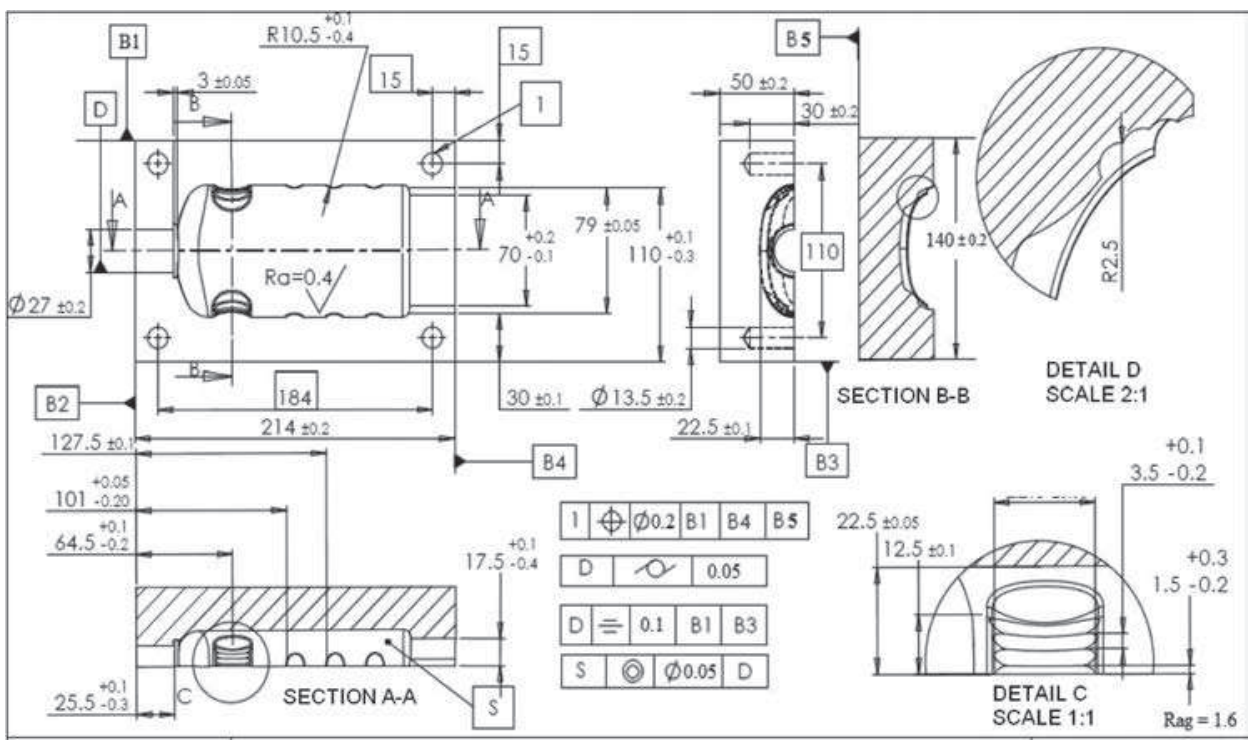

FIGURE 17 Workpiece configuration. 


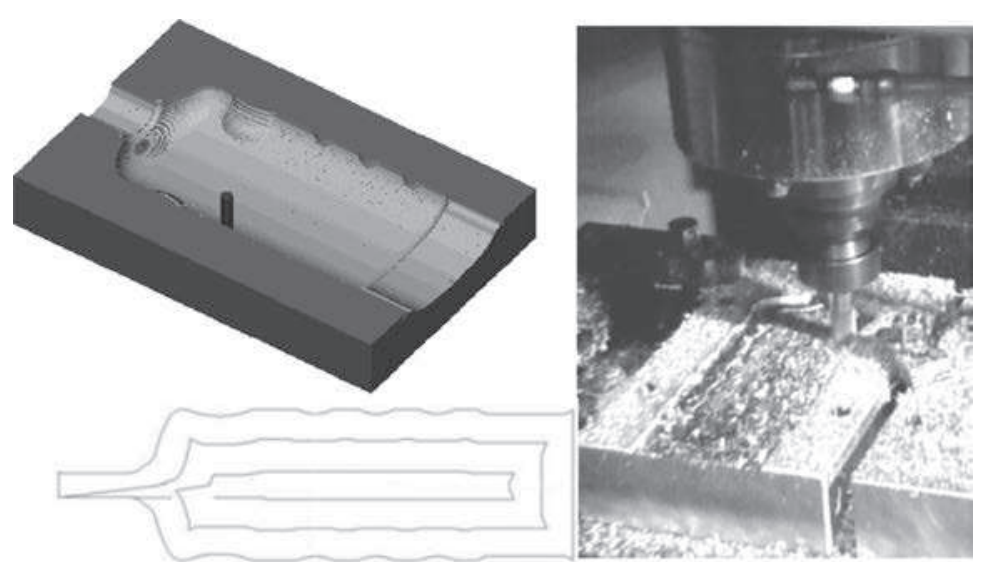

FIGURE 18 Simulation and machining of the injection moulds.

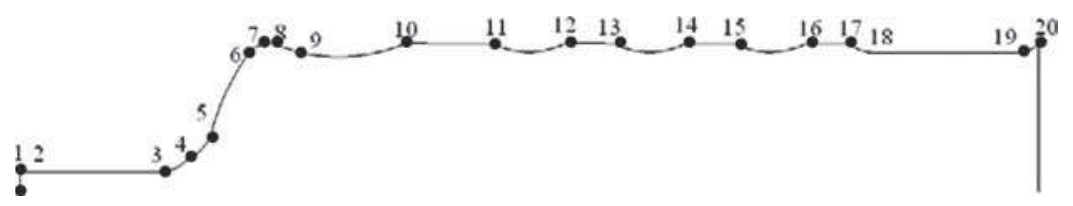

FIGURE 19 Tool center paths during sweeping the machined shape.

Figure 19. The choice of these points aims to distinguish $\gamma$ equation according to the type of combination between linear (G01) and circular interpolation (G02 and G03).

Figure 20 and Figure 21 present the theoretical and the experimental feed rates, respectively.

At points $4,8,10,11,12,13,14,15,16,17$, and 20 , the trajectory presents a discontinuity in tangency. This discontinuity is eliminated by adding a circle arc which is function of the tolerance value. The length of this

TABLE 4 Results of the Analytical Solution of the Orientation Angle $\gamma$ and Fillet Radius $R c$

\begin{tabular}{|c|c|c|c|c|c|}
\hline Points & $\begin{array}{l}\text { Connection } \\
\text { between }\end{array}$ & Equation of $\gamma$ & $\gamma\left({ }^{\circ}\right)$ & $\begin{array}{l}\text { Discontinuity/ } \\
\text { continuity }\end{array}$ & $\begin{array}{c}\text { Fillet } \\
\text { radius } R c\end{array}$ \\
\hline 3 & G1G3 & $90+\frac{\theta}{2}-\kappa+\alpha$ & 90 & continuity & - \\
\hline 4 & G3G3 & $\frac{\theta_{1}}{2}+\frac{\theta_{2}}{2}+\kappa_{1}-\kappa_{2}$ & 30.7 & Discontinuity & 0.57 \\
\hline 5 & G3G2 & $\frac{\theta_{2}}{2}-\frac{\theta_{1}}{2}+\kappa_{1}-\kappa_{2}$ & 8.4 & Discontinuity & 10.9 \\
\hline 6 & G2G2 & $\frac{\theta_{1}}{2}+\frac{\theta_{2}}{2}+\kappa_{1}-\kappa_{2}$ & 4 & Discontinuity & 6.68 \\
\hline 7 & G2G1 & $90+\frac{\theta}{2}-\kappa+\alpha$ & 85.5 & Discontinuity & 6.68 \\
\hline 11 & G2G3 & $\frac{\theta_{1}}{2}-\frac{\theta_{2}}{2}+\kappa_{1}-\kappa_{2}$ & 20 & Discontinuity & 0.75 \\
\hline 20 & G3G1 & $90+\frac{\theta}{2}+\kappa-\alpha$ & 219.2 & Discontinuity & 0.024 \\
\hline
\end{tabular}




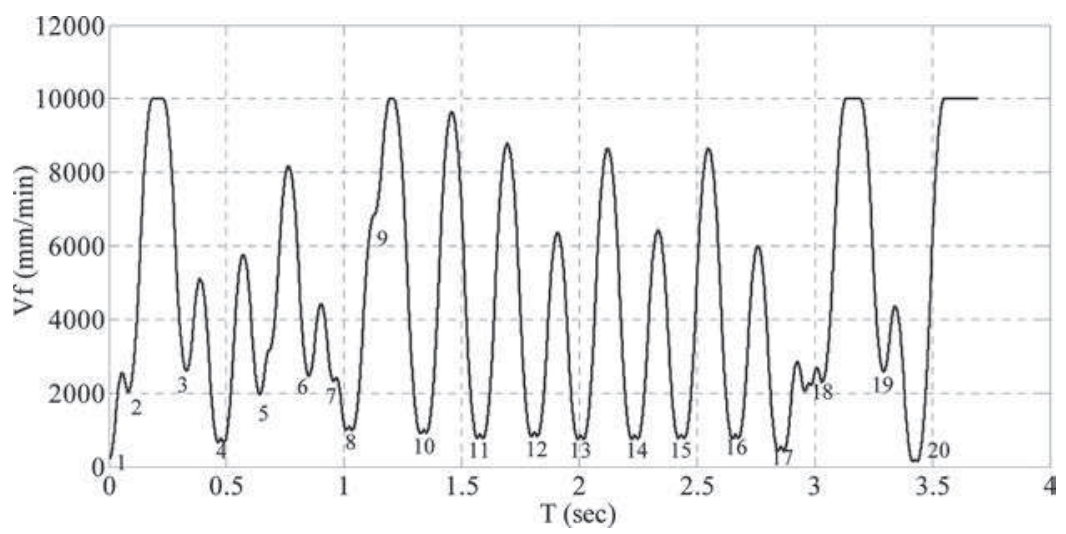

FIGURE 20 Theoretical variation of feed rate in function of time $V_{f p r o g}=10000 \mathrm{~mm} / \mathrm{min}$.

adding circle arc is very small. Then, the maximum feed rate can be limited by the interpolation cycle time.

In the experimental profile, the absence of acceleration and deceleration phase at these points (as shown in Figure 21) can be explained by:

- The maximum feed rate calculated by the theoretical interpolation cycle time $\left(t_{c y}=2 \mathrm{~ms}\right)$ is higher to the experimental value. This phenomenon is well met in the work of (Lavernhe et al., 2008).

- The tool path generated by the Siemens CNC (G641) at transition of the discontinuity in tangency is a polynomial trajectory approximation of circle arc (Pessole et al., 2012; Sinumerik, 2006) and this can also justify the disparity between theoretical and experimental results.

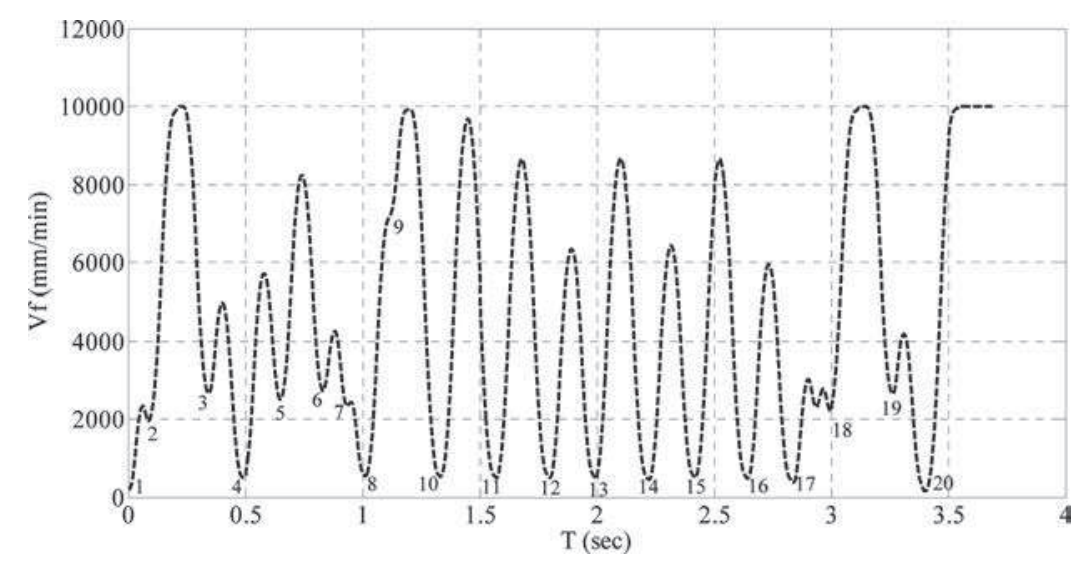

FIGURE 21 Experimental variation of feed rate in function of time $V_{f p r o g}=10000 \mathrm{~mm} / \mathrm{min}$. 
For the theoretical study, the ratio of the total time that would be required if the feed rate were a programmed value $V_{f p r}$ og to the actual required machining cycle time $r 1$ is calculated $T_{\text {cmod }}$ (as shown in Figure 22). For a programmed feed rate equal to $10,000 \mathrm{~mm} / \mathrm{min}, r 1$ is $8.011 \%$ of the total machining cycle time and $15.98 \%$ for $8000 \mathrm{~mm} / \mathrm{min}$.

$r 1$ is given by:

$$
r_{1}=\frac{\text { Time }\left(V_{f p r o g}\right)}{T_{c \bmod }}
$$

The percentage $r 1$ decreases by increasing the value of the programmed feed rate. This means that the feed rate does not always reach the programmed value during the machining process, especially when we used the important feed rates. To determine the impact of the feed rate variation on the machining cycle time, this last is calculated with and without taking the variation of the feed rate into account.

For a programmed feed rate $V_{\text {fprog }}=10,000 \mathrm{~mm} / \mathrm{min}$, the total machining cycle time calculated by Cam Software is given by:

$$
T_{c V_{\text {fprog }}}=\frac{l_{\text {tot }}}{V_{f p r o g}}=1.5 \mathrm{sec}
$$

When we used a variable feed rate the total machining cycle time is given by:

$$
T_{c \bmod }=3.7 \mathrm{sec}
$$

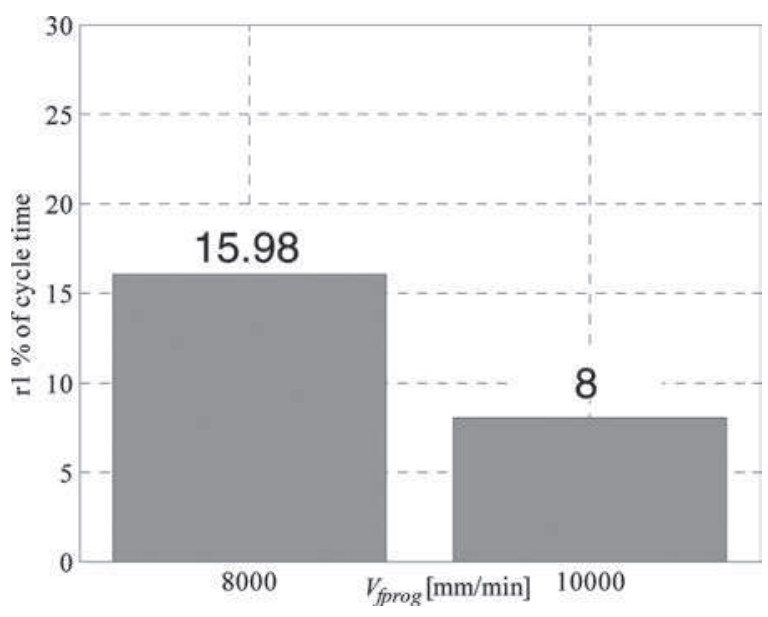

FIGURE 22 Representative graph of using percentage of the programmed speed. 
The report $\rho$ showed that the estimated cost is much higher than the actual cost:

$$
\rho=\frac{C_{a c t}}{C_{\text {est }}}=\frac{C_{m} T_{c \mathrm{mod}}}{C_{m} T_{c V_{\text {fprog }}}}=\frac{T_{c \bmod }}{T_{c V_{\text {fprog }}}} \simeq 2
$$

$C_{\text {est }}$ : The estimated cost is calculated as a function of the time $T_{c V_{\text {frong }}}$ calculated by CAM Software.

$C_{a c t}$ : The actual cost is calculated as a function of the simulated time $T_{c \text { mod. }}$.

This study shows us that the time calculated by CAM Software (the trajectory length/programmed feed rate) is not representative of the real machining time. It can be concluded that the importance of this shift should be taken into account during the calculation of the time and the cost of machining.

\section{CONCLUSIONS}

It is noted that in the context "HSM," it is important to study the response of machine during the machining process. Indeed, modeling the laws of motion axes and the actual trajectory at discontinuities is necessary to identify the machine behavior. The important numbers of discontinuities generates a significant instability of the real feed rate, which implies an increasing machining time and non-compliance with the programmed feed rate. This phenomenon leads to productivity issues and an underestimation of the cost of machining for the industry.

In this article, a theoretical and experimental study of the feed rate evolution in HSM for a tool path containing linear and circular interpolations is presented. The aim of this study is to investigate the response of the machine tool during any type of discontinuity between linear and circular contours in different combinaison. This can be determined from the following investigation:

- Identification of the type of a discontinuity at points where different trajectories meet;

- Calculation of the fillet radius value, which will be inserted at a discontinuity in tangency;

- Expression of the feed rate variation during a linear and circular interpolation;

- Estimation of the machining cycle time with a maximum error of $5 \%$. 
The theoretical study was developed in two parts. The first part was devoted to modeling geometryof the tool path, itinvolves calculating the radius between linear and circular interpolations in different combinations in relation to the errore imposed on the piece design. The second part focuses on the feed rate modeling with tangency continuity.

The experimental study is based on elementary tests, which leads to the determination of the influence of the tool path geometry on the feed rate evolution. An industrial case has been studied to validate models.

Our next work will be concentrated on developing a calculation interface for automating the process of determining the feed rate evolution and the estimated time and cost of production. This enables the industrial to minimize the time needed to establish the estimated cost.

\section{ACKNOWLEDGMENT}

The authors gratefully acknowledge the valuable help rendered by SIAF manufacture during the course of the experimental study.

\section{NOMENCLATURE}

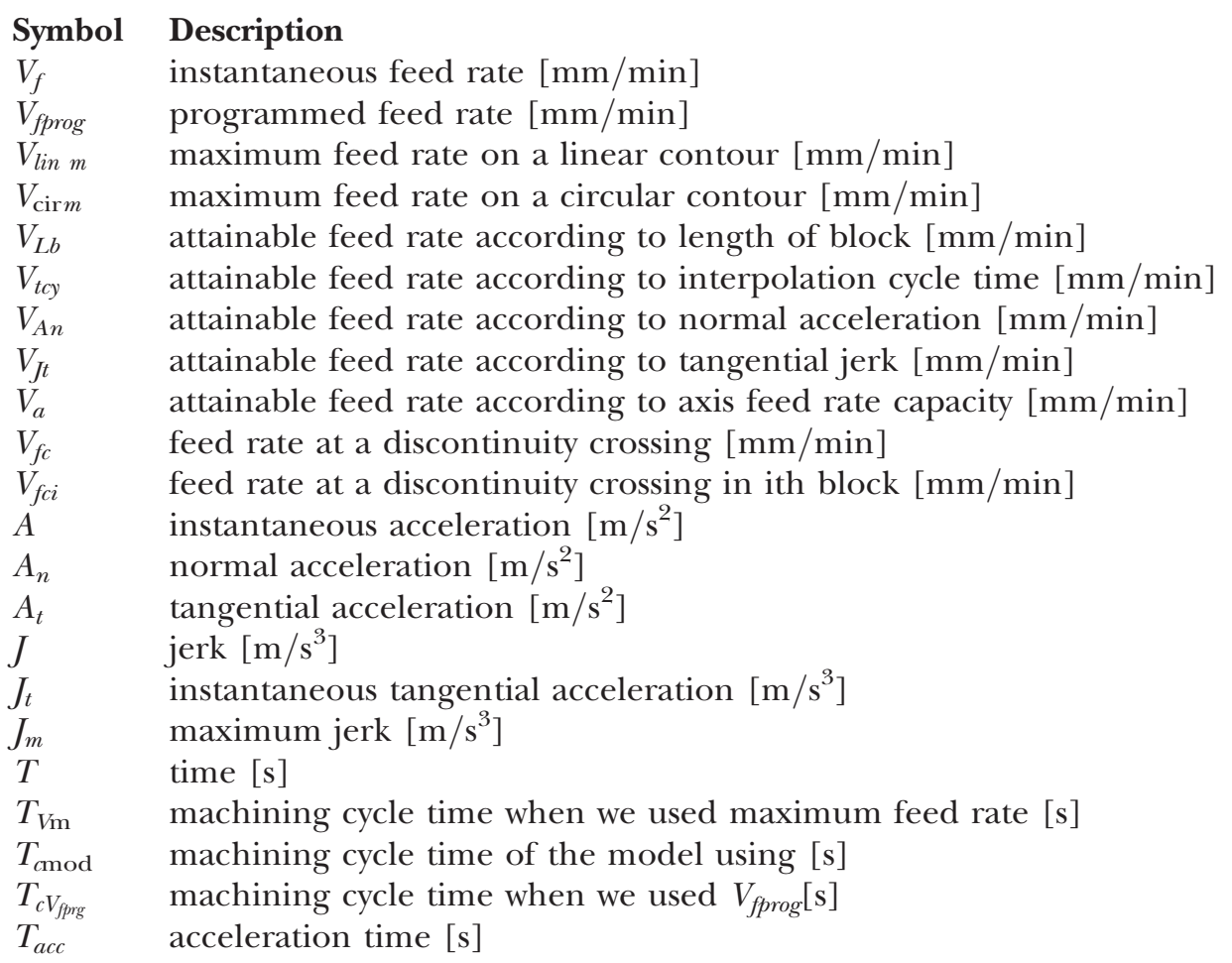




$\begin{array}{ll}T_{d e c} & \text { deceleration time }[\mathrm{s}] \\ t_{c y} & \text { interpolation cycle time }[\mathrm{s}] \\ \delta t & \text { circular transition block crossing time }[\mathrm{s}] \\ S & \text { curvilinear abscissa [mm] } \\ R ; R_{1} ; R_{2} & \text { workpiece curvature radius }[\mathrm{mm}] \\ R_{C} & \text { fillet radius }[\mathrm{mm}] \\ L_{l i n} & \text { length of the linear tool path of each block }[\mathrm{mm}] \\ L_{c i r} & \text { length of the circular tool path of each block }[\mathrm{mm}] \\ l_{t o t} & \text { total length of tool path }[\mathrm{mm}] \\ \varepsilon & \text { imposed error }[\mathrm{mm}] \\ T T I & \text { tolerance of trajectory interpolation }[\mathrm{mm}] \\ \gamma & \left.\text { orientation angle }{ }^{\circ}\right]\end{array}$

\section{REFERENCES}

Albert, M.; Ciuranaa, A.J.; Rodrigue, C.A. (2007) Experimental analysis of dimensional error vs. cycle time in high-speed milling of aluminium alloy. International Journal of Machine Tools $\mathcal{E}$ Manufacture, 47: 236-246.

Bearee, R.; Barre, P.J.; Bloch, S. (2004) Influence of high-speed machine tool control parameters on the contouring accuracy. Application to linear and circular interpolation. Journal of Intelligent and Robotic Systems, 40: 321-342.

Dugas, A. (2002) Simulation d'usinage de formes complexes, Phd thesis, IRCCYN, EcoleCentrale Nantes.

Dugas, A.; Lee, J.-J.; Hascoët, J.-Y. (2002) High speed milling-Solid simulation and machine limits. Integrated Design and Manufacturing in Mechanical Engineering, Kluwer Academic Publishers, New York, pp. 287-294.

Erkorkmaz, K.; Altintas, Y. (2001) High speed CNC system design. Part I: Jerk limited trajectory generation and quintic spline interpolation. International Journal of Machine Tools E Manufacture, 41: 1323-1345.

Held, M.; Spielberger, Ch., A. (2009) Smooth spiral tool path for high speed machining of 2D pockets. Computer-Aided Design, 41: 539-550.

Helleno, A.L.; Schützer, K. (2006) Investigation of tool path interpolation on themanufacturing of die and molds with HSC technology. Journal of Materials Processing Technology, 179: 178-184.

Heng, M.; Erkorkmaz, K. (2010) Design of a NURBS interpolator with minimal feed fluctuation and continuous feed modulation capability. International Journal of Machine Tools $\mathcal{E} \odot$ Manufacture, 50: 281-293.

Lavernhe, S.; Tournier, C.; Lartigue, C. (2008) Optimization of 5-axis high-speed machining using a surface based approach. Computer-Aided Design, 40: 1015-1023.

Moneral, M.; Rodriguez, C.A. (2003) Influence of tool path strategy on the cycle time of high-speed milling. Computer-Aided Design, 35: 395-401.

Pateloup, V. (2005) Amélioration du comportement cinématique des machines outils UGV-Application au calcul de trajets d'évidement de poches, Phd thesis, Blaise Pascal - Clermont II University.

Pateloup, V.; Duc, E.; Ray, P. (2004) Corner optimization for pocket machining. International Journal of Machine Tools E Manufacture, 44: 1343-1353.

Pateloup, V.; Duc, E.; Ray, P. (2010) B-spline approximation of circle arc and straight line for pocket machining. Computer-Aided Design, 42: 817-827.

Pessoles, X.; Landon, Y.; Rubio W. (2010) Kinematic modelling of a 3-axis NC machine tool in linear and circular interpolation. International Journal of Advanced Manufacturing Technology, 47: 639-655. DOI 10.1007/s00170-009-2236-z.

Pessoles, X.; Redonnet, J.-M.; Segonds, S.; Mousseigne, M. (2012) Modelling and optimising the passage of tangency discontinuities in NC linear paths. International Journal of Advanced Manufacturing Technology, 58: 631-642. DOI 10.1007/s00170-011-3426-z. 
Rauch, M.; Duc, E.; Hascöet, J.Y. (2009) Improving trochoïdal tool paths generation and implementation using process constraints modelling. International Journal of Machine Tools E $\mathcal{E}$ Manufacture, 49: 375-383.

Siller, H.; Rodriguez, C.A.; Ahuett, H. (2006) Cycle time prediction in high-speed milling operations for sculptured surface finishing. Journal of Materials Processing Technology, 174: 355-362.

Sinumerik (2006) Manuel de programmation Notions de base 840Dsl/840Disl/840D/840Di/810D.

Tang, Y. (2006) Optimization strategy in end milling process for high speed machining of hardened die/moldsteel. Journal of University of Science and Technology Beijing, 13: 240.

Tapie, L.; Mawussi, B.K.; Anselmetti, B. (2007) Circular tests for HSM machine tools: Bore machining application. International Journal of Machine Tools $\mathcal{E}$ Manufacture, 47: 805-819.

Wang, L.; Cao, J. (2012) A look-ahead and adaptive speed control algorithm for high-speed CNC equipment. International Journal of Advanced Manufacturing Technology, DOI 10.1007/s00170-012$3924-7$.

Yong, T.; Narayanaswami, R.A. (2003) Parametric interpolator with confined chord errors, acceleration and deceleration for NC machining. Computer-Aided Design, 35: 1249-1259. 